Pontifícia Universidade C $_{\text {atólica }}$

DO RIO DE JANEIRO

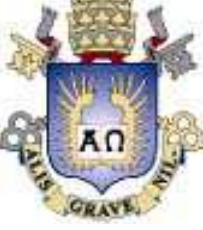

Irecê Fraga Kauss Loureiro

\title{
Aplicação de Opções Reais ao Setor de Circuitos Integrados
}

Dissertação de Mestrado

Dissertação apresentada como requisito parcial para obtenção do título de Mestre pelo Programa de Pós-Graduação em Administração de Empresas da PUC-Rio.

Orientador: Leonardo Lima Gomes 
Pontifícia Universidade Católica $_{\text {and }}$

DO RIO DE JANEIRO

Irecê Fraga Kauss Loureiro

\section{Aplicação de Opções Reais ao Setor de Circuitos \\ Integrados}

Dissertação apresentada como requisito parcial para obtenção do título de Mestre pelo Programa de PósGraduação em Administração de Empresas da PUCRio. Aprovada pela Comissão Examinadora abaixo assinada.

Prof. Leonardo Lima Gomes Orientador Departamento de Administração - PUC-Rio

Prof. Luiz Eduardo Teixeira Brandão Departamento de Administração - PUC-Rio

Profa. Kátia Rocha IPEA

Profa. Monica Herz Coordenadora Setorial do Centro de Ciências Sociais - PUC-Rio

Rio de Janeiro, 17 de agosto de 2010 
Todos os direitos reservados. É proibida a reprodução total ou parcial do trabalho sem autorização da universidade, da autora e do orientador.

\section{Irecê Fraga Kauss Loureiro}

Graduou-se em Engenharia de Produção pela Universidade Estadual do Rio de Janeiro (UERJ) em 2000. Cursou MBA em Administração no IAG - PUC-Rio em 2007. É gerente no Departamento de Indústria Eletrônica do Banco Nacional de Desenvolvimento Econômico e Social (BNDES) desde 2003 e atua no fomento, análise e acompanhamento de projetos e empresas da indústria eletrônica brasileira.

Ficha Catalográfica

Loureiro, Irecê Fraga Kauss

Aplicação de opções reais ao setor de circuitos integrados / Irecê Fraga Kauss Loureiro ; orientador: Leonardo Lima . - 2010.

60 f. : il. (color.) ; $30 \mathrm{~cm}$

\section{Dissertação} (Mestrado)-Pontifícia

Universidade Católica do Rio de Janeiro, Departamento de Administração, Rio de Janeiro, 2010.

Inclui bibliografia 
A Deus que enche a minha vida de bênçãos. Ao meu marido, que sempre esteve ao meu lado e compreendeu as noites fora de casa para assistir aulas e as madrugadas de muito estudo. Aos meus filhos, que chegaram durante a elaboração deste trabalho. A minha mãe e irmã que sempre me incentivaram, me apoiaram e foram influências essenciais na minha decisão de trabalhar no BNDES e, posteriormente, de cursar o mestrado. 


\section{Agradecimentos}

Ao Banco Nacional de Desenvolvimento Econômico e Social, que financiou o curso e viabilizou a realização deste projeto. Ao meu orientador, Leonardo Lima, que soube compreender a demanda pelo estudo do setor de circuitos integrados e enfrentar uma proposta de trabalho inusitada em sua carreira. Aos professores que participaram da Comissão examinadora. A todos os professores e funcionários do Departamento pelos ensinamentos e pela ajuda. A todos os amigos e familiares que de uma forma ou de outra me estimularam ou me ajudaram. 


\section{Resumo}

Loureiro, Irecê Fraga Kauss; Gomes, Leonardo Lima. Aplicação de Opções Reais ao Setor de Circuitos Integrados. Rio de Janeiro, 2010. 60p. Dissertação de Mestrado - Departamento de Administração, Pontifícia Universidade Católica do Rio de Janeiro.

A indústria eletrônica cada vez mais adquire importância na economia mundial. O uso de partes e peças eletrônicas deixou de ser exclusivo da informática e passou a permear setores diversos. Cresce a relevância da atração de investimentos em circuitos integrados para a manutenção da diferenciação, dos investimentos em pesquisa e desenvolvimento e até mesmo da competitividade da indústria brasileira. Neste contexto, este trabalho pretende avaliar uma oportunidade de investimento no desenvolvimento de uma planta de circuitos integrados no Brasil utilizando um exemplo numérico. Dadas as diversas incertezas em um projeto deste tipo, foi utilizada a metodologia de opções reais para analisar o investimento em um start-up de circuitos integrados. Ressalta-se que a volatilidade do retorno de uma base de empresas do setor foi considerada como proxy para a volatilidade do ativo-objeto, o fluxo de caixa de uma empresa de circuitos integrados instalada no Brasil. Assim, implementou-se uma metodologia para a obtenção da volatilidade de um projeto de start-up. De posse da volatilidade estimada, o valor das opções reais foram calculados com base no modelo binomial proposto por Cox, Ross \& Rubinstein. Os resultados demonstram que a incorporação das incertezas e a análise das opções de espera e de expansão trazem valor significativo ao projeto.

\section{Palavras-chave}

Opções reais; semicondutores; circuitos integrados; análise de investimento; start-up. 


\section{Abstract}

Loureiro, Irecê Fraga Kauss; Gomes, Leonardo Lima (Advisor). Real Options Application on Integrated Circuits Sector. Rio de Janeiro, 2010. 60p. MSc. Dissertation - Departamento de Administração, Pontifícia Universidade Católica do Rio de Janeiro.

Electronic industry is getting more important in world economy. The use of electronic parts is not an exclusive use of information technology but also of many sectors. It is becoming more important to attract investments in integrated circuits in order to differentiate products, to invest in research and development and even to increase brasilian industry competitiveness. In this context, this study intends to evaluate an investment opportunity of an integrated circuits company with a numeric example. Considering many uncertainties that exist on a project like this, real options theory was used in order to analyse an integrated circuits start-up investment. It is important to mention that the volatility of the return of a group of companies was used as a proxy to obtain the underlying risky asset volatility, as the underlying risky asset is the cash flow of an integrated circuits company built in Brazil. Therefore, this methodology was implemented to find a start-up project volatility. With this estimated volatility, the real options values were calculated based on the binomial model proposed by Cox, Ross \& Rubinstein. Results show that incorporating uncertainties and analysing wait and expansion options raise substantial value to the project.

\section{Keywords}

Real options; semiconductors; integrated circuits; investment analysis; start-ups. 


\section{Sumário}

1 Introdução 11

2 Referencial Teórico 15

2.1. Análise de Investimentos no Setor de Circuitos Integrados 15

2.2. Teoria das opções reais 17

2.3. Modelo de Copeland \& Antikarov 20

2.4. Estimativa da volatilidade de uma ação com base em dados históricos 23

3 Circuitos Integrados: Contexto do Mercado 25

4 Modelo e Metodologia $\quad 29$

4.1. Análise determinística: fluxo de caixa descontado 29

4.1.1. Taxa de desconto 33

4.2. Modelagem das incertezas: cálculo da volatilidade 35

4.3. Modelo binomial e análise de opções reais 39

4.3.1. Opções reais cabíveis 39

4.3.2. Modelo 1: caso base opção de espera 40

4.3.3. Modelo 2: caso base opção de espera mensal 42

4.3.4. Modelo 3: caso base com opção de expansão 43

5 Resultados 48

6 Conclusão e Sugestões de Trabalhos Futuros 50

7 Referências Bibliográficas $\quad 52$ 


\section{Lista de tabelas}

Tabela 1: Balança Comercial Brasileira em

Componentes Eletrônicos em US\$ Milhões

Tabela 2: Resumo das Premissas Adotadas

Tabela 3: Estrutura do Fluxo de Caixa

Tabela 4: Cálculo da Taxa Livre de Risco

Tabela 5: Cálculo do Custo de Capital Próprio

Tabela 6: Empresas Utilizadas Para o Cálculo da

Volatilidade Histórica 


\section{Lista de figuras}

Figura 1: Abordagem Geral: Processo em quatro passos

Figura 2: Evolução anual do mercado de semicondutores em US\$ Bilhões

Figura 3: Modelos de negócio da cadeia

produtiva de circuitos integrados

Figura 4: Evolução do indicador de valor das empresas de circuitos integrados

Figura 5: Árvore de Eventos - Modelo 1

Figura 6: Modelagem da opção de espera

Figura 7: Árvore de Decisão - Modelo 1

Figura 8: Árvore de Eventos - Modelo 3

Figura 9: Modelagem da opção de espera associada à opção de expansão. Parte $\mathrm{A}$

Figura 10: Modelagem da opção de espera associada à opção de expansão. Parte $B$

Figura 11: Modelagem da opção de espera associada à opção de expansão. Parte $\mathrm{C}$ 